\title{
Pasolini y Zurita: torturas alimentarias
}

\section{Pasolini and Zurita: Food Torture}

\author{
Magda Sepúlveda Eriz ${ }^{1}$ \\ Facultad de Letras, Pontificia Universidad Católica de Chile. Santiago, Chile. \\ msepulvu@uc.cl
}

\section{Resumen}

La película Saló de Pier Paolo Pasolini y el libro Zurita de Raúl Zurita comparten la representación de la violencia sobre los cuerpos como un efecto de la alianza que se produce entre la política y la ley, propia de los estados totalitarios. En ellos, toda la política se ejerce mediante leyes que no tan solo norman los espacios públicos, sino también los privados, lo que incluye las actividades sexuales, alimentarias y de defecación, entre otras. Ambos autores discuten esta práctica de la ley ejercida en espacios cerrados. Pasolini hace del palacio que encierra a los prisioneros una metonimia de todo tipo de nación y Zurita liga los territorios de las naciones latinoamericanas a ejercicios de exterminio.

Palabras clave: Zurita, Pasolini, poesía chilena, dictadura, tortura.

\section{Abstract}

Italian filmmaker Pier Paolo Pasolini's Saló film and Zurita, poetry book by chilean author Raúl Zurita, share the depiction of violence over human bodies as an effect of the alliance between Politics and the Law, a very common feature on totalitarian governments. All actions are exerted by means of laws dealing not only with public spaces, but also private ones, including sexual intercourse, feeding, and defecation. Both authors discuss these actions in the context of closed locations. Pasolini turns the palace and its prisoners into a metonymy for all nation, and Zurita links the territories of Latin-American nations to extermination practices.

Keywords: Zurita, Pasolini, Chilean poetry, Dictatorship, Torture.

1 Este artículo se inscribe dentro del proyecto Fondecyt 1120264, "Comidas y bebidas en la poesía chilena", cuya investigadora responsable es quien suscribe este texto. 
El director de cine italiano Pier Paolo Pasolini y el poeta chileno Raúl Zurita comparten una misma visión sobre la ley. El autor de Zurita (2011) titula a uno de los poemas centrales del libro: "Pier Paolo Pasolini le pone cámara a los países muertos". ¿En qué consiste este vínculo? La cercanía de ambos radica en describir cómo el exceso de reglamentos pretende dirigir y secuestrar la vida del ser humano. Tanto la película como el libro de poesía diseñan imágenes para referirse a diversos abusos producidos por la ley: desde el encierro, la violencia sexual, la obligación de comer al modo de los animales, la coacción a alimentarse de heces, las amputaciones y hasta la eliminación dentro de un marco legal.

Para Pasolini y Zurita, hay algo dislocado en el hecho de estar sometido a leyes. En este sentido, ambos coinciden con el filósofo italiano Giorgio Agamben, quien caracterizó al ser humano como un cuerpo sobre el cual se aplica la ley de un territorio específico desde el mismo momento del nacimiento. A esta condición la llamó la "nuda vida". En "nuestro siglo [XX] las democracias parlamentarias han podido transformarse en Estados totalitarios [que determinan] qué forma de organización resultaría más eficaz para asegurar el cuidado, el control y el disfrute de la nuda vida" (155). Para Agamben, entonces, toda nación es productora de "nuda vida".

Pasolini crea una película en la cual, por sujeción a la ley, se produce la "nuda vida"; esta es Saló o los 120 días de Sodoma, de 1975, financiada por Alberto Grimaldi. En ella se plantea una disquisición sobre los ámbitos que puede alcanzar la ley como forma de producir orden y organización. En la ley existe fundamentalmente obligatoriedad y prohibición respecto de la manera de proceder; por ello, quienes exageran en la ley desconfían del actuar humano libre. Mientras más severidad desean, más desconfianza poseen hacia sus semejantes. Saló y Zurita retratan los cuerpos tras el ejercicio de la hipernormatividad. En ambos textos, los cuerpos son vejados y destruidos.

El título del poema "Pier Paolo Pasolini le pone cámara a los países muertos" nos lleva inmediatamente a preguntarnos: ¿qué son los países muertos para este poeta? Los países muertos son, para Zurita, todas las naciones latinoamericanas que tienen tumbas políticas no reconocidas; por ello, denomina también a los países como "nichos". Así, Zurita escribe: "Nicho Argentina. [...] País desaparecido del horror tras los cuarteles mecánica de la armada y otros. Desde allí el viento sopló sobre la pampa inexistente y apagándose se vieron las masacradas caras. Amén” (Zurita 358). Zurita nombra a Argentina como nicho porque recuerda la Escuela de Mecánica de la armada argentina, más conocida bajo la sigla ESMA, que fue centro de torturas durante la dictadura militar. Por allí pasaron 5.000 prisioneros que se encuentran desaparecidos. Por tanto, es una fosa.

Así mismo, Zurita relaciona a Bolivia con una fosa: "Del amor paceño desaparecido quedó en lenguas de aymaras un dolor tan herida la palomitay que cayó guerreando. Dice así: de derrota en derrota la más querida fue cavando esta fosa” (Zurita 361). Para hablar de Bolivia, el poeta alude ahora a la palabra "fosa" y recuerda un tiempo más antiguo, en el cual comienza el exterminio del pueblo aymará. Bolivia es tam- 
bién un nicho mortuorio. De esta forma, Zurita simboliza cada país latinoamericano como una fosa. Es decir, las naciones, en tanto espacios cerrados, devienen campos de exterminio, tal como connota Pasolini en su película.

El director italiano comprendió como pocos los mecanismos de exterminio ligados a los estados totalitarios. Ellos se generan por el uso constante de una violencia brutal, tal como la podemos ver en Saló. El film narra tres días de los 120 que imaginó el Marqués de Sade en su novela Las 120 jornadas de Sodoma, publicada en 1785. La película está dividida en cuatro partes: "Antesala del infierno", "Círculo de las manías", "Círculo de la mierda" y "Círculo de la sangre”, y cada una de ellas es un avance en horror legal respecto de la anterior, lo que vuelve insoportable su visión. A su vez, cada uno de estos horrores sobre el cuerpo está poetizado en el texto de Zurita.

Tanto en el "Círculo de las manías", como en el "Círculo de la mierda” y el "Círculo de la sangre" Pasolini inicia la secuencia con la narración de una mujer. El director crea una cercanía entre relato verbal y vejación. Después de cada relato, a cargo de una de las tres meretrices protagonistas de la película, acontece el conjunto de aberraciones. La Sra. Vaccari cuenta historias de violaciones y después estas ocurren. La Sra. Maggi relata historias en que el placer sexual se relaciona con la ingesta de caca y luego se obliga a una prisionera a tragar excremento. Finalmente, la Sra. Castelli narra torturas con máquinas y con animales, las que se concretan después. Por tanto, hay una secuencia entre discurso verbal y acción, de acuerdo con la cual lo que ocurre con los cuerpos está posibilitado primero en la palabra. Tal como sucede con la ley. Zurita no indaga en los discursos verbales que facilitan la agresión, pero poetiza los efectos desde voces mayoritariamente insólitas de muertos y detenidos desaparecidos que hablan y dan cuenta de lo sufrido.

\section{Las leyes, la antesala del infierno}

En "Antesala del infierno" se establece la condición de los prisioneros a través del discurso del Duque, uno de los hombres poderosos, quien les informa a los demás su calidad de secuestrados e indefensos desde un balcón. La cámara muestra la distancia de altura entre los dirigentes y los reglamentados, equivalente a su distancia en derechos. El Duque les dice a los jóvenes prisioneros, nueve chicos y nueve chicas: "Nadie en la tierra sabe que estáis aquí. En todo lo que concierne al mundo, vosotros ya estáis muertos y estas son las leyes que regularán aquí dentro vuestra vida" (Pasolini 21 '). El primer acto de violencia ha sido detener, secuestrar y llevar hasta un palacio aislado a estos jóvenes. El segundo hecho violento es verbalizarles que están muertos, siendo que están vivos. El tercero es indicarles las leyes que regulan su habitar en ese espacio. De este modo, la soberanía del sujeto la poseen los gobernantes del espacio, de la nación, y no el propio sujeto. 
El palacio de Saló, ubicado en la región homónima del norte de Italia es una metonimia del funcionamiento de la nación. Una de las escenas centrales de "Antesala del infierno" es la firma del reglamento por los cuatro hombres que regirán el palacio, su Excelencia (el Magistrado), el Presidente, el Duque y el Monseñor. Cada uno de estos personajes funciona como metonimia de la conformación de la sociedad: las leyes, el poder ejecutivo, la aristocracia y los directores espirituales, todos ellos elaboran un acuerdo sobre los habitus que deberán tener los cuerpos de los ciudadanos. En otras palabras, el poder tiene un corpus acordado sobre los cuerpos y sus funciones. La cámara filmadora va a reforzar ese poder a través de planos generales, al mostrarlos habitualmente bajando desde escaleras y con dominio de los espacios, los que se representan tan cuadriculados y normados como los reglamentos que han diseñado.

Tanto el palacio de Saló como el Chile, de la Junta Militar se rigen por un gran número de leyes que sirven a los intereses de los cuatro poderosos. Ni en el palacio ni en el Chile militar hay instituciones, sino únicamente leyes. Las instituciones tienen un propósito, por ejemplo, la escuela tiene el objetivo de educar para crear sujetos libres: en los años sesenta, un individuo capaz de trabajar en equipo, en la década del 2000. Se necesitan pocas leyes para echar a andar la máquina de una institución. Las dictaduras, por el contrario, requieren una serie de leyes para mantener incólume su propósito de destrucción de cuerpos.

Los cuatro dirigentes de Saló funcionan como los cuatro miembros de la Junta Militar: carabineros, fuerza aérea, militares y marina. La junta se inaugura con una serie de bandos militares. ¿Por qué esta necesidad de reglas? Porque operan bajo el supuesto de que los seres humanos actúan incorrectamente. De ellos podría ser la frase: "Si los hombres supieran lo que es el Bien, o supieran amoldarse a él, no tendrían necesidad de la ley" (Deleuze 73). De manera que quien desea generar más leyes se mueve por una concepción del ser humano como sujeto maligno. El palacio de Saló está lleno de reglas, o bien, la antesala del infierno está en los reglamentos.

En Zurita, la condición de carencia de derechos está expresada por la voz poética de un sobreviviente al horror legal. En el poema "150973", título numérico que cifra la fecha 15 de septiembre de 1973, y que alude a la forma de desubjetivizar a los prisioneros en los campos de concentración, el sobreviviente dice: "Allí donde nos encontrábamos llorando y recordando / nuestra tierra y uno le dijo al guardia 'tenemos / derechos' y él le contestó 'eso díganselo a Dios"' (Zurita 506). De esta manera, Zurita recrea su estadía en el barco carguero Maipo y coincide con Pasolini en la idea de que los prisioneros políticos son seres humanos vivos que están muertos.

En Pasolini, los abusos ocurren al interior de un castillo alejado de la ciudad, que se cierra al modo de una prisión clandestina. Los reglamentos abusivos funcionan sobre territorios cerrados. Zurita poetiza los espacios chilenos de encarcelamiento. En el poema "Tus patrias la desgracia”, se recrean los lugares de reclusión: 


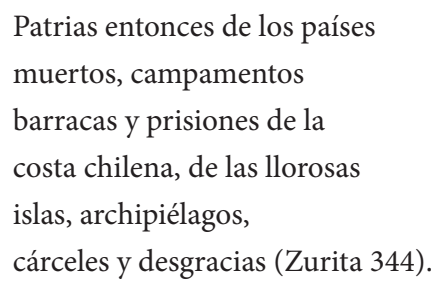

La patria engendra los centros de reclusión, como el campamento Pisagua, las barracas de Tres Álamos, la Isla Dawson y la isla Quiriquina, entre otros lugares que dan origen a los títulos de los poemas, tal como Saló es el título de la película. En estos espacios impropios de reclusión, los prisioneros están dados por muertos y, por tanto, se ejercen toda clase de vejámenes sobre sus cuerpos. De manera que a través del título "Pier Paolo Pasolini le pone cámara a los países muertos", Zurita cita todas las aberraciones de la película y las trae al escenario chileno.

Tanto Pasolini como Zurita trabajan artísticamente lo que sucede con los abusos. Pasolini hace emerger la violencia como consecuencia de leyes o relatos verbales que los permiten, pues concibe la ley como el órgano que legitima los abusos. El espacio físico de Saló, región de Italia cercana al núcleo fascista donde se instaló Mussolini, pasa a representar la nación. Zurita también hace equivaler nación y exterminio. Cada nación es un nicho, porque bajo sus leyes se vuelve lícito encerrar y someter al cuerpo a una serie de severos reglamentos. De esta manera, para ambos artistas, las leyes en territorios cerrados son la antesala del infierno.

\section{Donde el "yo" no es soberano de su cuerpo}

Pasolini resuelve visualmente los modos en que los órdenes totalitarios inscriben sobre el cuerpo humano. Por el solo hecho de nacer en esos territorios, el cuerpo le pertenece a la nación. Es decir, todo lo que entra y sale del cuerpo está regulado por las leyes de ese espacio: tanto la sexualidad, la alimentación como la defecación. Pasolini lleva esto hasta el extremo en la secuencia de la Sra. Vaccari o "Círculo de las manías", en que la meretriz relata abusos sexuales, principalmente contra niñas, y luego muestra escenas de violaciones de prisioneras a la vista de los cuatro regentes y de los guardias. A eso le suma la escena de una comida, donde dos chicas deben alimentarse al modo de los perros.

Los regímenes alimenticios, -qué, cómo y cuándo se come- son formas de control sobre el cuerpo del otro. Mediante la manipulación de la cantidad, la forma y los horarios de ingesta, se elimina la soberanía del "yo" sobre su cuerpo. El "Círculo de las manías" escenifica no solo la posibilidad de tomar posesión sexual de otro sometido en cualquier momento, sino también cómo se lo controla provocándole hambre y obligándolo a comer al modo de los animales. En Saló, dos chicas desnudas y atadas 
con correas para perros deben comer la carne que se les deja en el suelo. Toda la distinción entre ser humano y animal, anhelo de los estados modernos, se extravía en esa escena. A otra chica le dan un panecillo con clavos añadidos a la masa, para que ella lo muerda y dañe su paladar. La escena de los clavos es el reverso del pan que resurrecta; aquí, el pan mata, en alusión a las políticas de alimentación ${ }^{2}$ de los estados autoritarios.

Zurita examina también cómo la dictadura impuso un orden sexual violento. En el poema "Fellatio", el hablante lírico describe las agresiones que sufre y la violencia sexual a que es obligada una prisionera amiga suya:

La punta de la culata me rompió los dientes y

penetró mi boca.

La vi mientras se venía y luego el resplandor

del golpe.

Mi amiga se la chupaba a un amigo y fue duro.

Amargas fellatio las del amanecer (Zurita 497).

Zurita titula su poema "Fellatio", jugando con el borde pornográfico con el cual esa palabra se utiliza, pero al poner la oración "me rompió los dientes" entendemos que la acción sexual es obligada. La dictadura busca romper el lenguaje en ambos abusados: los dos prisioneros están siendo violentados en la boca. Así la dictadura, tanto en el hablante al cual le quebraron los dientes, como en la muchacha a quien coaccionaron al sexo oral.

Zurita poetiza no sólo la agresión desde un captor hacia un secuestrado, sino también la violencia forzada entre prisioneros, como los cuerpos que fueron obligados a morderse entre ellos, en un intento por volver animal al ser humano. En el poema “Por qué me muerdes?” la voz relata esta escena:

- Y eran como destrozados

cielos sus caras para

abajo, mordidas, gritando

De los saltos del Grito, rápidos y

deshielos de los Asesinos, ojos

del Frío, nieves y cataratas [...]:

- Mordiéndose los pedazos,

Agarrotados, pidiéndose

amor entre esos pedreríos (Zurita 149).

2 En varios productos de ficción sobre estados totalitarios, la comida homogénea ocupa un lugar central. En Un mundo feliz (1932) de Aldous Huxley, los habitantes consumen soma, una droga que reemplaza las realidades del presente y las transforma en imágenes felices, transformándose en una herramienta de la estabilidad social. En la película Brasil (1985), dirigida por Terry Gilliam, la comida tiene números: menú uno, dos o tres. 
Cuando Zurita escribe "saltos del Grito" o "amor entre pedreríos" crea una mezcla del territorio corporal con el territorio del paisaje, lo que genera la forma retórica característica de su escritura, la cual le permite producir un discurso enaltecedor sobre las víctimas. Zurita modifica escrituralmente el deseo de la dictadura de volver animales a los prisioneros obligándolos a morderse. Si los cuatro mandamases del horror querían ver a los prisioneros ocupar la boca como hocico, al modo de las bestias, Zurita produce la contrapartida de ocupar la boca en el lenguaje y crear para ellos la lengua de una nueva retórica.

La escritura enaltecedora de Zurita permite cambiar de signo las atrocidades del Estado totalitario. Si los cuatro militares pensaron los cuerpos de los fallecidos como comida para animales y peces, Zurita habilita la transformación de los arrojados al mar en el cuerpo que resurrecta, de ahí el título del poema, "Inri": "Sorprendentes carnadas llueven desde el cielo. / Sorprendentes carnadas sobre el mar. Abajo el mar, / arriba las inusitadas nubes de un día claro" (Zurita 93). La inscripción INRI alude a lo que fue considerado el delito de Jesús, a saber, denominarse Rey de los Judíos (Iesvn Nazarenus Rexivdaeorum). Zurita, al atribuir la misma inscripción a los prisioneros políticos acusados de querer revolucionar Chile, los torna una subjetividad acusada injustamente y, además, un cuerpo que resurrecta. En la escritura del poeta chileno, el desacato al tabú alimentario de dar un cadáver humano como comida vuelve culpable a quien lo hace y pone en un sitio heroico al fallecido.

Zurita poetiza el efecto sobre la cultura que producen las aberraciones de la dictadura. La atribución de estos estados totalitarios sobre el derecho a la vida y a la muerte, causan en una herida dolorosa que la voz describe como inscrita geológicamente. En el libro Zurita, los cuerpos lanzados al mar hieren el territorio geográfico:

Los arrojaron desde aviones y era como ver el cielo precipitándose en el Pacífico responden en otros sueños las desplomadas playas Sí: cuando todo el dolor cayó en el mar del dolor y no era yo sino un dios de hambre (Zurita 84).

En la poesía de Zurita, el horror de no ser enterrado y servir, en tanto cadáver, de alimento para los peces, queda inscrito en el territorio. Por ello, el poeta buscó realizar una inscripción distinta en el paisaje chileno y escribió en los acantilados del desierto de Atacama "Ni pena, ni miedo" en 1992. El trazado de este geoglifo gigante buscaba sanar el territorio de lo que había sufrido (Escribir en el desierto. Zurita). El daño se había producido porque, culturalmente, nuestro cadáver no es alimento ni para otro humano, ni para los animales; esta es una interdicción alimentaria de larga data que las dictaduras transgredieron. De manera que quién es soberano del cuerpo, cómo se relaciona sexualmente con otros cuerpos, cómo se alimenta e incluso de quién es un cadáver son todos asuntos regulados por leyes. A estas preguntas las dictaduras responden de una sola manera: el dueño de ese cuerpo y de su cadáver es el Estado totalitario. 


\section{Obligado a comer excrementos}

La tercera parte de Saló, titulada "El círculo de la mierda", tiene como coprotagonista a una chica que llora por su madre, quien ha caído al río por defenderla de los secuestradores. Ella es obligada, como castigo por su amor materno, a comer heces. Al contrario de la filial prisionera, la protagonista y relatora de esta secuencia, la Sra. Maggi, que gozaba la sexualidad en vínculo con la defecación, había asesinado a su madre. En el film de Pasolini, la distancia que el ser humano pone respecto de las heces constituye, precisamente, el índice de su condición de humano, que es lo que tratan de aniquilar los Estados totalitarios.

La cultura, señala Levi Strauss en "Breve tratado de etnología culinaria”, comienza cuando el humano come con su boca y no con su ano, es decir, cuando no come o bebe sus heces. En Ezequiel 4, 12, la palabra bíblica dice: "tu comida será una torta de cebada, cocida en fuego de estiércol humano, y la prepararas donde la gente te vea" (905). De esta manera, la humanidad diferencia la comida de sus heces humanas, que sólo le pueden servir de estiércol. Pero en el horror de Pasolini, como en el de Zurita, las heces pasan a convivir con los secuestrados e incluso se convierten en su comida. La convivencia de los prisioneros con sus excrementos es una de las formas de vulneración de lo humano; por esto, los que practican el horror no los dejan ir al baño y los obligan a defecar en el mismo lugar donde habitan.

Los prisioneros de Saló son obligados a defecar solo cuando sus captores los autorizan y a participar de una boda homosexual forzada donde se sirven fecas como plato principal. La figura de la Sra. Maggi connota al perverso excrementicio, que tiene una lectura dañada de su sí mismo como cuerpo arrojado por el cuerpo materno. Ella es la basura arrojada por su madre como feca; por ello, su goce está ligado a materias excrementicias.

La voz autoficcionalizada de Zurita relata cómo, desde el primer momento de su detención, lo hicieron convivir con heces. A partir de su secuestro en el internado de estudiantes de la Escuela Santa María en Valparaíso, hasta su traslado al buque carguero Maipo, el hablante lírico experimenta la cercanía obligada con las heces: "Caigo. La fuerza del primer golpe me dobla en dos haciéndome cerrar instintivamente los ojos [...] Abro los ojos en uno de los saltos del camión. El excremento de los cuerpos que van encima me ahoga mientras el cielo cae" (520). El prisionero ya no se puede separar de las heces, y así él mismo se transforma en lo inmundo. Esta obligación a convivir con la suciedad tiene por propósito que el prisionero destruya su identidad al considerarla sucia, y desee emerger hacia una nueva forma de subjetividad considerada limpia.

Los estados totalitarios, simbolizados en Pasolini y Zurita, aspiran a controlar cada aspecto del ser humano, tanto sus desempeños públicos como los privados. La política se ha transformado ya no sólo en un ejercicio de la plaza pública, sino también en una práctica que atañe a los dormitorios y a los baños privados. 


\section{Sufrir la amputación corporal}

La cuarta parte de Saló se titula "Círculo de la sangre", y en ella se escenifican las amputaciones y asesinatos que sufren los prisioneros del palacio: es ya la destrucción total del cuerpo humano y, por ello, la parte final de la película. Al cierre, dos soldados que han participado en estas agresiones bailan juntos un vals, connotando con ello la desensibilización ante la violencia y la relación entre una melodía que se repite al modo de un mantra y el secuestro de la conciencia. Otra película sobre estados totalitarios que cierra con una banda sonora relajante es Brasil; en ambos films la ideología que lleva a matar a otros humanos anula la conciencia del aquí y ahora del asesino.

Retomando. El título del poema "Pier Paolo Pasolini le pone cámara a los países muertos" de Zurita es más que una mera mención al director; es una cita por la cual ambos comparten un punto de vista, referido a cómo las leyes pueden ser perversas, al extremo que llevan al cercenamiento de los cuerpos. La voz creada por Zurita describe los cercenamientos con la misma verosimilitud realista que Pasolini. Así describe la voz poética:

las sábanas de los paisajes doblándose sobre el palerío y sobre ellas
las mutiladas piernas los quemados torsos los rotos
cuellos doblándose y doblándose como se iba doblando
el país muerto entre los astillados brazos de las palizadas (Zurita 291).

Al referir "las mutiladas piernas", "los quemados torsos" o "los rotos cuellos", Zurita crea la figura del horror sin decir el origen de ese horror, a diferencia de Pasolini, quien muestra la secuencia relato-acción. Zurita tiende a omitir que la dictadura se atribuyó a sí misma un programa de "limpieza" política y que desde ese relato se autorizó a exterminar a los grupos políticos de izquierda. Para ello, denominó a la gente de izquierda "extremistas" y a los que practicaban la "limpieza" héroes, es decir, creó un lenguaje que permitía el cercenamiento y el asesinato. Zurita poetiza los cuerpos agredidos asumiendo el "yo" en algunos poemas del libro y, en otros, mostrando la distancia de la víctima traumatizada que observa todo como si fuese una película. Esa visión de la realidad como simulacro es en la que Zurita ahonda en el poema que alude al cineasta Pasolini.

Las mutiladas piernas y los quemados dorsos referidos ficcionalmente en la película de Pasolini son representados por alusión al director italiano:
Allí donde las montañas se alargan cerrando el mar y
donde filmadas a lo más Pasolini también violadas
también muertas también masacradas las caras
chilenas (Zurita 350).

La voz solo puede representar el Estado tanatopolítico de la dictadura como si fuese una película de Pasolini. En ambos artistas, la condición humana libre es caducada y 
en su lugar se instala la nuda vida, un ser humano vuelto un pedazo de carne sobre el cual se inscriben leyes y reglamentos, pero no derechos.

La relación entre cuerpo y ley fue una preocupación para los escritores que se iniciaron en el campo cultural durante la dictadura; por ello, Diamela Eltit nombra también a Pasolini en sus trabajos. En su libro de ensayos Emergencias, la escritora manifiesta su consonancia con la tematización de los efectos políticos sobre el cuerpo que elabora el director italiano, y afirma su sintonía con la idea de "construir una obra en contra de las normas autoritarias con una radicalidad poética y teórica que lo alejó de toda posibilidad de complacencia cuando exploró los centros de los disturbios e hizo de la pasión y de la sexualidad un instrumento político" (Eltit 44). Eltit, Pasolini y Zurita comparten la indagación artística sobre los modos en que el poder de la ley llega hasta la vida privada de los ciudadanos y los destruye.

En conclusión, el film de Pasolini discurre sobre la generación y la aplicación de la ley en los estados totalitarios, tal como el poemario de Zurita recrea los efectos de esa ley dictatorial sobre los cuerpos. En ambos textos, los seres humanos no solo están sujetos a la ley, sino que son prisioneros de ella. Los dos productos estéticos trabajan sobre el objetivo final de la ley autoritaria: normar los cuerpos en su sexualidad, en sus prácticas alimenticias y en su defecación, para mostrarlos después como homogéneos, idénticos entre sí, sin ningún atisbo de libertad, la cual es considerada grosera e inmunda. Así, el que sigue dócilmente la ley autoritaria no es justo y, por el contrario, quien desconfía de ella, examinándola desde la pregunta por el bien comunitario institucional, se encamina hacia la construcción de relaciones amorosas.

\section{Referencias}

Agamben, Giorgio. Homo Sacer. El poder soberano y la nuda vida. Valencia: Pre-Textos, 2010. Medio impreso.

Deleuze, Gilles. Sacher, Masoch y Sade. Córdoba: Editorial Universitaria de Córdoba, 1969. Medio impreso.

Eltit, Diamela. Emergencias. Escritos sobre literatura, arte y política. Santiago: Planeta, 2000. Medio impreso.

Escribir en el desierto. Zurita. Dir. Colin Still. Optic Nerve. Medio fílmico. www. opticnerve.co.uk

Levi-Strauss, Claude. Mitológicas III: El origen de las buenas maneras en la mesa. México: Fondo de Cultura Económica, 1968. Medio impreso.

Sagrada Biblia. Santiago: Universidad Católica, 2012. Medio impreso.

Saló o los 120 días de Sodoma. Dir. Pier Paolo Pasolini. Metro Goldwyn Meyer, 1975. Medio fílmico.

Zurita, Raúl. Zurita. Santiago: Universidad Diego Portales, 2011. Medio impreso. 